\title{
Fundamental Analysis of Insurance Industry Operations and GDP Increase in Nigeria
}

\author{
Andrew O. Agbada ${ }^{1} \&$ Casmir C. Osuji ${ }^{1}$ \\ ${ }^{1}$ Accounting, Banking and Finance Department, Faculty of Management Sciences, Delta State University, Asaba \\ Campus, Delta State, Nigeria \\ Correspondence: Andrew O. Agbada, Accounting, Banking and Finance Department, Faculty of Management \\ Sciences, Delta State University, Asaba Campus, Delta State, Nigeria. E-mail: andrewoagbada@ gmail.com
}

Received: May 1, 2020

doi:10.5430/ijfr.v11n4p275
Accepted: June 17, 2020

Online Published: July 7, 2020

URL: https://doi.org/10.5430/ijfr.v11n4p275

\begin{abstract}
This study evaluated Insurance Industry Operations (IIO) and GDP Increase in Nigeria. Insurance company core functions, namely: 'Offering of financial protection to Consumers 'Investment of Funds from Premium charged' and 'Provision of Foreign Insurance Services' served as proxies for IIO. Survey design was adopted for the collection of data which were analyzed using Pearson Product-Moment Correlation Coefficient (r). The findings showed that the models for hypotheses one and two passed the test of significance but hypothesis three failed it. Thus we concluded that the variables 'Offering of financial protection to Consumers' and 'Investment of funds from Premium' can be considered relevant to policies formulated to affect GDP Increase in Nigeria but the variable 'Provision of Foreign Insurance Services' cannot. We therefore recommend that Managers of Insurance companies should seek to employ innovative strategies in service delivery and sustained efforts should be made by stakeholders to export insurance products across borders to other countries.
\end{abstract}

Keywords: insurance, industry, operations, GDP increase, Nigeria

JEL Classification: C40; C51; G10; G22.

\section{Introduction}

Universally, Insurance is a cardinal and essential branch of Finance and its operations play vital role in providing safety environments for economic activities to take place. Though Insurance appears somewhat unpopular to most households and businesses in the Nigerian society for obvious reasons, it has however been an integral part of overall business operations. In developed and some emerging economies of the world where people express trust for insurance services, it plays great roles in boosting the economy. To effectively start this discussion and for the purpose of clarity, it is necessary to give a concise definition and explanation of the term 'Insurance'. In its most simplified form, Insurance is a strategy of protecting individuals, households and business entities from financial loss. It involves risk management; a technique designed to reduce or possibly eliminate financial risk or hedge against unforeseen or accidental loss. According to Chikeleze and Echekoba (2008), Insurance is a contract whereby one party called the insurer, in return for a consideration called the premium, undertakes to pay the other party called the insured a sum of money or its equivalent in kind upon the happening of specified event that is contrary to the interest of the insured. From another perspective, Merriam-Webster dictionary defined Insurance as 'an agreement in which a person makes regular payments to a company and the company promises to pay money if the person is injured or dies or to pay money equal to the value of something (such as a house or car) if it is damaged, lost, or stolen'. For a more detailed explanation of the terms involved in insurance operations, the company providing the service is the 'insurer' while the individual or corporate body purchasing the insurance service receives a contract known as 'insurance policy' and the holder thereof is referred to as a 'policyholder' or the 'insured'. The unforeseen or accidental loss being insured against may involve a thing, an object, article, substance, a human being, commodity, et cetera in which the insured has what is known as 'insurable interest. The insurable interest may be as a result of ownership of something precious, a property for instance or pre-existing relationship as in the case of the relationship between spouses or being in possession of an object, et cetera.

The fact that risk is inherent or deep-rooted in human social life, business and economic activities makes insurance institutions of great importance for sustainable economic growth and development in any nation. Thus, the insurance 
industry has vital roles to play in the enhancement of the economic life of individuals and businesses or corporations and the entire economy. Diacon and Carter (2007), argued that insurance industry operations requires the employment of scarce economic resources that could be used to produce other goods and services. In return for the use of these resources, the industry produces variety of services that people and industries need for development. The Insurance industry thus helps to stimulate the economy by offering financial protection for consumers against a wide range of risks and uncertainty, some of which include: injuries at work place, vehicle accidents, flooding, et cetera. Insurance thus, drives the economy by helping businesses to mitigate risks and disasters that would otherwise cause financial duress resulting from such challenges. Sajid, Arpah and Angappan (2017) emphasized that business of insurance helps to drive growth. At its best, the protective safety net of insurance enables businesses to undertake high-risk and high-return activities. Consequently, businesses run successfully and that translates to more job creation and increase in other economic activities. Another way the Insurance industry stimulates the economy is by helping to finance economic projects. This is mostly pronounced in developed economies of the world. American Insurance Association (AIA) argued that property-casualty insurers operating in the U.S have more than $\$ 1.4$ trillion invested in the economy. Typically, the insurance companies gather large pool of funds from premiums. The proportion of the funds not utilized for paying claims and running operating expenses is invested in stock and shares, real estate, government and corporate bonds, et, cetera. The invested funds provide support for economic project development in the country. Sajid, Arpah and Angappan (2017), affirmed that Insurance businesses help to provide employment opportunities and capital funds for productive investments. It promotes trade and commerce activities and enables households and companies to mitigate losses, thus it provides financial stability. These outstanding functional traits translate to development in every sector of the economy and ultimately, to economic growth.

There is a consensus from empirical and theoretical literatures that insurance operations affect macroeconomic variables positively. This assertion is buttressed by Haykn (2014), who studied the role of Insurance in the World economy and its effect on macroeconomic indicators and averred that insurance companies provide increasing employment opportunities and protection to businesses in order to increases Gross Domestic Product (GDP), the main macroeconomic indicators that measures the level of output in a country. Consequent upon this role, Insurance contributions to the economy affects the Balance of Payments (BoP) positively. Haykn K. (2014), argued that in developed countries such as Germany, England, Switzerland, France, et, cetera, Insurance services are vital part of the economy. In these countries people trust insurance, and for this reason they insure all assets in famous insurance companies. The insurance market thus helps the Insurer and the insured to meet and their daily transactions constitute part of the activities that helps the economy to grow positively resulting in GDP Increase. Most policyholders in these countries faithfully pay their premiums consistently without default to the insurance companies who in turn use the premiums to finance investments and productive activities in the economy. The products and services so financed leads to increase in overall GDP value in the economy. The growth in the market facilitates increase in employment and it translates to improving financial stability, thus insurance could be said to be a reliable system that improves the economy. The insurance industry thus plays crucial roles in these developed countries. However, for most developing countries like Nigeria, the opposite appears to be the case for two fundamental reasons. First, Insurance companies appear evasive and people hardly trust them particularly with respect to demand for claim. Secondly, premiums are hardly regularly paid as at when due by policyholders. The combination of these features somewhat affect the performance of the Nigerian Insurance industry negatively.

Fundamental analysis is simply about the use of fundamentals or basic roles as strategy to evaluate businesses and possibly to analyze how the roles could facilitate performance in an industry. Though Insurance companies undertake several economic activities, there are some fundamental functions that subsume or encompass other functions and aid economic growth positively and rapidly. These functions are universal and facilitate economic growth in every nation. Diacon and Carter (2007), argued that these fundament functions enable the Insurance industry play special roles in the economy of nations and it leads to increase in GDP. General consensus in finance literatures affirmed that Insurance industry stimulates an economy by performing strategic or fundamental functions which include: 'Offering of financial protection to Consumers; 'Investment of Funds from Premium charged' and 'Provision of Foreign Insurance Services'. Succinctly, offering of financial protection for consumers helps Insurance companies transfer the risk of losses to enable businesses thrive. The premium insurers charge for carrying out insurance services constitutes an enormous source of funds for investments and for financing projects. Also, the provision of foreign insurance services to residents of the rest of the world enhances the Balance of Payment (BoP) of nations. The aforementioned insurance services help boost and invigorate economic activities with an attendant positive effect on GDP Increase. It is on this note that this study seeks to carry out a fundamental analysis of Insurance Industry operations and GDP Increase in Nigeria. The study thus paid special attention to these three 
fundamental roles that insurance companies play in the Nigerian economy. These functions serve as proxy for Insurance Industry Operations and have been adopted in this study as the independent variables to explain GDP Increase. GDP Increase refers to Economic growth. GDP is the most popular macroeconomic indicator or measure of the economic well-being of a country. GDP represents the market value of goods and services produced by a country during a given period of time, usually a year. In a nutshell, the study seeks to investigate how effective the Insurance industry operations in Nigeria are contributing to GDP Increase. This is the core motivation for conducting this research. Specifically therefore, the objective of the study is to determine to what extent is the Insurance industry operations affecting or impacting on GDP Increase in Nigeria.

\subsection{Hypotheses Formulation}

Based on the background and objective of the study stated above, we formulated three null hypotheses to be tested and from where valid inferences will be deduced and conclusion drawn. The null hypotheses states thus:

H01: There is no significant relationship between 'Offering of financial protection to Consumers' in the Insurance industry and 'GDP Increase' in Nigeria.

H02: There is no significant relationship between 'Investment of Funds from Premium charged' in the Insurance industry and 'GDP Increase' in Nigeria.

H03: There is no significant relationship between 'Provision of Foreign Insurance Services' in the Insurance industry and 'GDP Increase' in Nigeria.

\section{Review of Related Literature}

Insurance companies play very important roles as financial markets round the world. Their roles somewhat complement those of Banking institutions and the Capital markets. Jointly, the roles of these three specialized institutions and markets boost economic activities of nations. Specifically, Insurance provides protection for risks inherent in everyday life activities and in particular risks in financial operations. The insured has an obligation to pay specified amount as premium with a promise from the insurers to pay compensation should the events insured against occurs. According to Ozuomba (2013), Insurance is designed to protect the financial well-being of an individual, company or other entity in the case of unexpected loss. In a more elaborate form, we reiterate that Insurance contract is referred to as 'insurance policy' and the holder thereof is known as the policyholder or an insured. These contracts or policies vary in kind and structure depending on the type of contract. It could be informal or formal contract. The first type of insurance was the informal insurance being practiced by most communities and it is also known as 'self-insure'. This mechanism of micro-insurance has been popular in communities that cannot afford formal insurance policy for some reasons; in particular, as a result of transaction cost. These communities take to informal mechanism through pooling resources and contributions to cover future and probable, unforeseen expenses. This mechanism is referred to locally in Nigeria as 'Osusu'. It may also be carried out through building assets and also diversifying income. This informal insurance practice is growing fast because it helps participants to alleviate their welfare challenges. It also has the merit of avoiding transaction costs but the main disadvantage is lack of legal enforceable obligations amongst participants. Overall, this mundane insurance practices has helped and is helping communities to enhance economic activities and contributing immensely to GDP increase.

Though the informal insurance practices have been useful to communities and households, other formal types of Insurance contract existing in Nigeria and are contributing greatly to GDP Increase assume the following broad headings:

Property and Natural disasters Insurance: This involves insurance against special perils and notable here is policy against Fire, Earthquake and Tornados (FET). Ozuomba (2013), argued that there is an enormous potential for natural disaster and weather insurance to improve the performance of lower income economies, which tend to be more vulnerable to high volatility in incomes due to commodity price fluctuations and natural disasters resulting from poor building codes and infrastructures.

Transportation Insurance: This includes Marine, Aviation, Motor vehicles and transit insurance. Marine insurance covered risks in marine trade. According to Diacon and Carter (2007), Aviation insurance of hulls, cargo, freight and liability is available to aircraft owners, operators, manufacturers and as well as airport authorities. The Road Traffic Act of 1988 introduced compulsory minimum cover for all vehicles used in the road. In Nigeria, motor vehicle insurance commonly found are in the form of 'Third party' cover which gives unlimited protection against liabilities to third parties and the 'Comprehensive' type which covers risks to policyholder's own vehicle and as well as risks to third party. 
Personal accident, Sickness and Health Insurance: This includes all classes of insurance policy that cover the injury, sickness, death or prolonged life of policyholder. Collectively, these are known as 'Insurances of the person' (Diacon and Carter (2007)). Embedded in the above broad headings exist some other forms of formal insurance contracts or policies. However, the focus of this study is to appraise Insurance Industry operations in Nigeria using its fundamental functions to explain GDP Increase. The fundamental functions we reiterate as: Offering of financial protection for Consumers, Investment of Funds from Premium charged and Provision of Foreign Insurance Services. At this point, we wish to provide a distinct overview and concise analysis for each of these fundamental functions of Insurance.

Premium charged on transfer of Risk of Losses emanates from the fact that Insurance companies offer financial protection to consumers or policy holders. Insurance help businesses locally and internationally to mitigate risks and so, help sustain the economy and keep it viable and vibrant always. In Nigeria, businesses and households who are the major consumers of Insurance products are gradually realizing the magnitude of risks, dilemma and uncertainty they face during the course of carrying out their duties. Some of these risks ranges from accident at home, at work or on the high ways to accidental fire, flood from a big storm or other unforeseen disasters. Insurance is designed to cater for businesses whenever such uncertainties occur. The plan is designed to provide relief and financial protection to businesses and households. Iowa Insurance Institute (2020) opined that Insurance can help manage this uncertainty and potential loss by providing vital financial protection. Without it, many individuals in these situations would be financially strained and could even face bankruptcy. Indeed, Ward and Zurbruegg (2000) affirmed that in the absence of risk transferor entities like insurance companies, the volume of economic activities in the financial market would be much lower and hence will result in an economic loss. Another way that Insurance companies ameliorate risks is by providing safety education and training to consumers of their products. According to Weisbart (2018), to educate consumers on safety concerns, insurers collect and analyze information and disseminate financial and non-financial knowledge. They employ a wide variety of loss prevention personnel (e.g., safety engineers and fire prevention specialists) and medical professionals to study ways to protect lives and property. These ways, Insurance operations help drive GDP Increase in an economy. It must be noted that in protecting and helping businesses to thrive, premium are charged on such services. So, there are mutual benefits between the insurers that protects and the insured - the consumers being protected. This brings us to the discussion on Investment of Funds from Premium charged.

Investment of Funds from Premium charged is the second independent variable in this study. From our discussion above, premium charged on transfer of risk of losses is a kind of consideration for providing protections for insurance products consumers. Protecting the business gives it sustenance and aids the business to flourish. Meanwhile, these businesses pay premium which in turn helps Insurance companies acquire funds for investments and for financing economic projects. According to Iowa Insurance Institute (2020), insurers operating in the U.S. have more than $\$ 1.4$ trillion invested in the economy. Insurance companies typically invest premiums, or funds that are not used to pay claims and other operating expenses. The investments may be through stock, corporate and government bonds, and real estate mortgages. Beside investments, premium paid may be utilized to finance building construction and to provide other crucial support to economic development projects around the nation'. Sumegi and Haiss (2006), affirmed that Insurance companies are one of the biggest institutional investors in stock, bond and real estate markets and their possible impact on the economic development will rather grow than decline'. From theoretical and empirical literatures, we have deduced that investment of funds derived from premium charged has positive correlation with economic growth or GDP Increase. For example, in their study, Oyedotun and Adesina (2015) investigated the impact of insurance business on economic growth in Nigeria adopting GDP as dependent variable and Insurance investment, Total insurance premium and Total insurance claims as the independent variables. Their results showed that total insurance investment had significant positive link with GDP, while total insurance claims had significant negative effect on GDP. This implies that Insurance companies' investment was significant and relevant to policy formulated to affect GDP Increase. Etale (2019) investigated Insurance Sector Development and Economic Growth in Nigeria and concluded that the coefficient of the variable, 'Insurance investment (INV) has a significant positive impact on GDP at 5\% level and concluded that a unit increase in Investment will result in 0.11 units increase in GDP. The economic implication is that total insurance investment contributes significantly to the growth of the Nigerian economy. Also, Igbodika, Ibenta and Isaac (2016) investigated the contribution of insurance investment to economic growth in Nigeria and the results indicated that insurance sector investment had significant positive effect on economic growth in Nigeria.

The third independent variable is 'Provision of Foreign Insurance Services'. It is about the international aspects of insurance, mostly, the exportation of insurance products to the rest of the world to earn foreign exchange. This is the 
aspect of insurance services that affect Balance of Payment (BoP) positively in vibrant economies. Foreign Insurance Services may assume various transaction types or forms. First, when the policyholder or the insured purchased insurance policy from an insurer situated in another country. This refers to a 'cross-border' business. Secondly, when an insured purchases insurance policy from an insurer, though located in same country but the insurer Head office is situated in another country. In other words, it involves purchasing a policy from a branch of a foreign insurance company having foreign shareholders or ownership. That the branch is situated in a foreign country implies that dividends have to be remitted across an international border to the home country. The third transaction type is though the transaction between the insured and insurer took place locally in same country, the insurance relates to international movement of materials, or stocks or personnel (Diacon and Carter, (2007)). Foreign insurance transactions have dual advantages to the local economy. In the first instance, they enable foreign insurance companies provide employment opportunities to boost local economy. Haykn (2014) studied the Role of Insurance in the World Economy and its effect to Macroeconomic Indicators and averred that influential insurance companies such as AXA, Lloyds, Allianz, have big branches in developed and developing countries. Many people from different countries work in these insurance companies, so ample employment opportunities are being provided in these economies'. Secondly, these cross-border transactions affect the Balance of payments of the local economy positively. Provision of Foreign Insurance Services or Cross-border Insurance services may include such services as: the provision of life insurance and annuities, non-life insurance, freight insurance, standardized guarantees reinsurance, pensions and pension schemes, standardized guarantee schemes, et cetera. In all these transactions, Insurance Industry operations affect balance of payments positively. Deductions from the discussions above imply that Insurance Industry operations are capable of stimulating an economy positively through all the variables under discussion in this study. Haykn (2014) provides Table 1 to show the share of insurance in world macroeconomic indicators for the period 2010 to 2014. The table clearly portends that Insurance industry operations globally facilitate a significant share in some macroeconomic indicators and this affirms that the industry plays enormous role in world economy.

Table 1. Insurance share in world macroeconomic indicators

\begin{tabular}{llllll}
\hline Years & $\mathbf{2 0 1 0}$ & $\mathbf{2 0 1 1}$ & $\mathbf{2 0 1 2}$ & $\mathbf{2 0 1 3}$ & $\mathbf{2 0 1 4}$ \\
\hline Insurance share in GDP & $2.4 \%$ & $2.4 \%$ & $2.5 \%$ & $2.5 \%$ & $2.6 \%$ \\
Insurance share in employment & $3.1 \%$ & $3.4 \%$ & $3 \%$ & $3.2 \%$ & $4 \%$ \\
Insurance share in economic growth & $2.4 \%$ & $2.3 \%$ & $1.5 \%$ & $2.6 \%$ & $2.4 \%$ \\
Insurance share in balance of payments & $7 \%$ & $7 \%$ & $5.5 \%$ & $6 \%$ & $5 \%$ \\
\hline
\end{tabular}

Source: Haykn (2014), The Role of Insurance in the World Economy and its effect to Macroeconomic Indicators.

The above is global records and it indicates clearly that Insurance share in Balance of Payments stood highest in percentages all through from 2010 to 2014. By implication, it means that the Provision of foreign Insurance services, otherwise, cross-border diversification of Insurance services or the exportation of insurance products to the rest of the world earned much revenue and enhanced Balance of payment position positively. Indeed, the practice of cross-border diversification of Insurance services is very common amongst financial institutions in Euro Area zone or the European Union countries striving for a single financial market. Conclusively, we wish to explore Insurance Industry Operations on the basis of its fundamental roles and GDP Increase with a view to drawing inferences and conclusions that could enhance the contributions of the industry operations to output growth in Nigeria.

\section{Research Methodology}

Research Methodology discussions are centered on the mechanisms, methods and techniques applied in accomplishing the research. For ease of discussion, the section is divided into sub-sections such as: Research design, definitions of study Population and Sample size; Sampling techniques and Questionnaire design and Statistical analysis techniques and Model specification. The section ended with Decision rule, the standards that justify whether an independent variable is significant and could be considered relevant to policies formulated to affect the dependent variable.

\subsection{Research Design, Definitions of Study Population and Sample Size}

The research design followed in carrying out this study is the 'Survey design' believed to be comprehensive enough to give intellectual idea of the study population. Questionnaire distribution was used to elicit respondents' opinion on the questions raised. By definition, Population is viewed as a group of people who inhabit a territory, or work in an 
organization or a group of organisms of same species inhabiting a given area or the entire aggregation of items from which sample can be drawn. More precisely, Creswell (2005), opined that Population is the broadest level in which a group of individuals or things under study possess one characteristic that distinguishes them from other group'. From the foregoing, the population of this study consists of employees of all Insurance institutions and markets operating in Nigeria and who are in middle and top levels of management cadre. From the population, we drew the Sample population from where the study data were selected. The Sample population consists of employees of all Insurance institutions and markets operating in the commercial cities in Edo and Delta States of Nigeria. The Sample size is made up of five hundred (500) employees in the categories specified. For a study of this nature, it is considered prudent that a Sample size of 500 employees is large enough to enable us draw inferences of general application.

\subsection{Sampling Techniques and Questionnaire Design}

The study utilized Random Sampling tactics in the collection of data. Random sampling involves randomly selecting elements in a sample whereby each element has equal chance of been selected. For this reason, it is considered free from favouritism and partiality. The survey instrument was broken down into two segments, the first was the demographic section and the second contains questions with answer options designed to follow the pattern of 'Item-Specific-Response-Options (ISRO). According to Wronski (2018), 'Item specific' means that response options are specific to a particular survey question, however, different questions may have different set of response options. Like the Likert scale, ISRO strategy has five point answer options but unlike the Likert scale, ISRO rating scales range from Very Affirmative; Somewhat Affirmative; Neither Affirmative nor Negative; Somewhat Negative to Very Negative and the scale is weighted 5, 4, 3, 2 and 1 respectively.

\subsection{Data Analysis Technique and Model Specification}

Pearson Product-Moment Correlation Coefficient (PPMCC) designated by the letter ' $r$ ' was employed in the analysis of data in this study. However, since ' $r$ squared' gives the Coefficient of Determination $\left(r^{2}\right)$, the parameter that measures the proportion of variation in the dependent variable that is explained by the independent variables, it was employed to buttress the analysis. These parameters were derived using the weights assigned to answer options and the frequencies of occurrences of answer options as obtained from field survey. PPMCC or ' $r$ ' is referred to as the 'Sample coefficient' and is indeed a genuine, undoubted and legit statistical parameter for providing measurement for the linear relationship between variables. It provides the direction of relationship, thus attesting to whether it is positive or negative and also gives the strength, the relative size or extent of relationship to indicate whether it is weak or strong. Usually, the value of PPMCC or ' $r$ ' could be stated in absolute figure as a decimal or in percentages for ease of interpretation. Obadan, (2012), argued that mathematically, a precise quantitative measurement of the degree of sample correlation between the variables $\mathrm{Y}$ and $\mathrm{X}$, that is, the PPMCC or $\left(\mathrm{r}^{\mathrm{X}}\right)$ could be computed using:

$$
\text { PPMCC or } \mathrm{r}^{\mathrm{x}_{\mathrm{y}}}=\frac{\sum(X-\bar{X})(Y-\bar{Y})}{\sqrt{\sum(X-\bar{X})^{2} \sum(Y-\bar{Y})^{2}}}
$$

Where: $\mathrm{r}^{\mathbf{x}_{\mathrm{Y}}}=$ Pearson's Product-Moment Correlation Coefficient between $\mathrm{X}$ and $\mathrm{Y}$ variables

$\mathrm{X}=$ Weighted Answer response options

$\mathrm{Y}=$ Frequency of Answer response options

$\sum=$ Summation sign

$\bar{X}=$ Mean of weighted Answer response options

$\bar{Y}=$ Mean of frequency of Answer response options

Without mincing words, the above expression is clumsy and cumbersome to manipulate mathematically. It employs the real values of variables under investigation. Owing to the intricate and compounded nature of equation 1, a less complex equation 2 using the deviations of the variables from their means strategy is employed to compute the value of PPMCC or $r^{x_{Y}}$. Equation 2 is expressed as:

$$
\mathrm{r}^{\mathrm{X}_{\mathrm{y}}}=\frac{\sum x y}{\sqrt{\sum x^{2} \sum y^{2}}}
$$


Where $\mathrm{x}=X-\bar{X} \quad$ (Deviation of weighted Answer options from their mean) and

$\mathrm{y}=Y-\bar{Y}$ (Deviation of Response Frequencies from their mean)

\subsection{Decision Rule of the Coefficient Derived}

According to Obadan (2012, Pearson's Product-Moment Correlation Coefficient PPMCC or 'r':

i. May assume values ranging -1 to +1 .

ii. When ' $r$ ' = zero, there is no relationship between the variables.

iii. When ' $r$ ' $=+1$, A perfect positive correlation exists between the variables.

iv. When ' $r$ ' $=-1$, A perfect negative correlation exists between the variables.

Coefficient of Determination $\left(\mathrm{r}^{2}\right)$ indicates the goodness of fit of the model.

\section{Data Presentation and Analysis of Results}

\subsection{Presentation of Data}

The data obtained from field survey were first presented in tables and in order to properly comprehend the distinguishing features of the frequency of response options for questions adopted for our analysis, they were again presented in a Column chart. Of the five hundred (500) structured questionnaires randomly distributed to elicit the opinions of the respondents in the sample population, four hundred and seventy five (475) were retrieved. This number constitutes $95 \%$ of total questionnaires distributed and is considered good enough to analyze the sample population.

\subsubsection{Presentation of Data for Hypothesis One (H01)}

Hypothesis one (H01) was formulated to test the relationship between Insurance Industry operations variable, namely 'Offering of financial protection to Consumers' and 'GDP Increase' in Nigeria. The question in the questionnaire that captured hypotheses one (H01) states thus:

'How contented or unsatisfied would you say that Offering of financial protection to Consumers by Insurance companies have contributed to GDP Increase in Nigeria?

Table 2. Responses frequencies for Hypotheses one (H01)

\begin{tabular}{lcc}
\hline & Response Frequencies & $\begin{array}{c}\text { Response Frequencies in } \\
\text { Percentages (\%) }\end{array}$ \\
\hline Very Contented & 115 & $24.21 \%$ \\
Somewhat Contented & 163 & $34.32 \%$ \\
Neither Contented nor Unsatisfied & 81 & $17.05 \%$ \\
Somewhat Unsatisfied & 82 & $17,26 \%$ \\
Very Unsatisfied & 34 & $7.16 \%$ \\
Total & 475 & $100 \%$ \\
\hline
\end{tabular}

Source: Field Survey, 2020.

We present in Table 2 the Response frequencies obtained for hypotheses one in figure and also in percentages. The first two categories of answer options indicate contentment and that implies that the respondents are contented that 'Offering of financial protection to Consumers' by Insurance companies has contributed to 'GDP Increase' in Nigeria. This duo constitutes $58.53 \%$ of total responses. However, at $58.53 \%$ the impact is just on the average which appears to suggest that though the variable 'Offering of financial protection to Consumers' made positive contributions, the relationship between the variables under review is not too strong. This result is somewhat true as it appears to reflect clients' poor attitude to insurance services emanating from controversies that trail insurance claims in Nigeria. However, more about this variable will be revealed on computation of Pearson's Product-Moment Correlation Co-efficient (PPMCC) or ( $\mathrm{r}$ ) and the Coefficient of Determination $\left(\mathrm{r}^{2}\right)$. Figure 1 displays the Column chart of the Response frequencies in percentages for the variable employed in evaluating Hypotheses one (H01). The chart shows clearly the distinct characteristics of the frequencies of each answer options for ease of interpretation. While the answer option 'Somewhat contented' stood highest at 34.32\%, the answer option 'Very Unsatisfied' stood lowest at $7.16 \%$. Others fell within this range. 


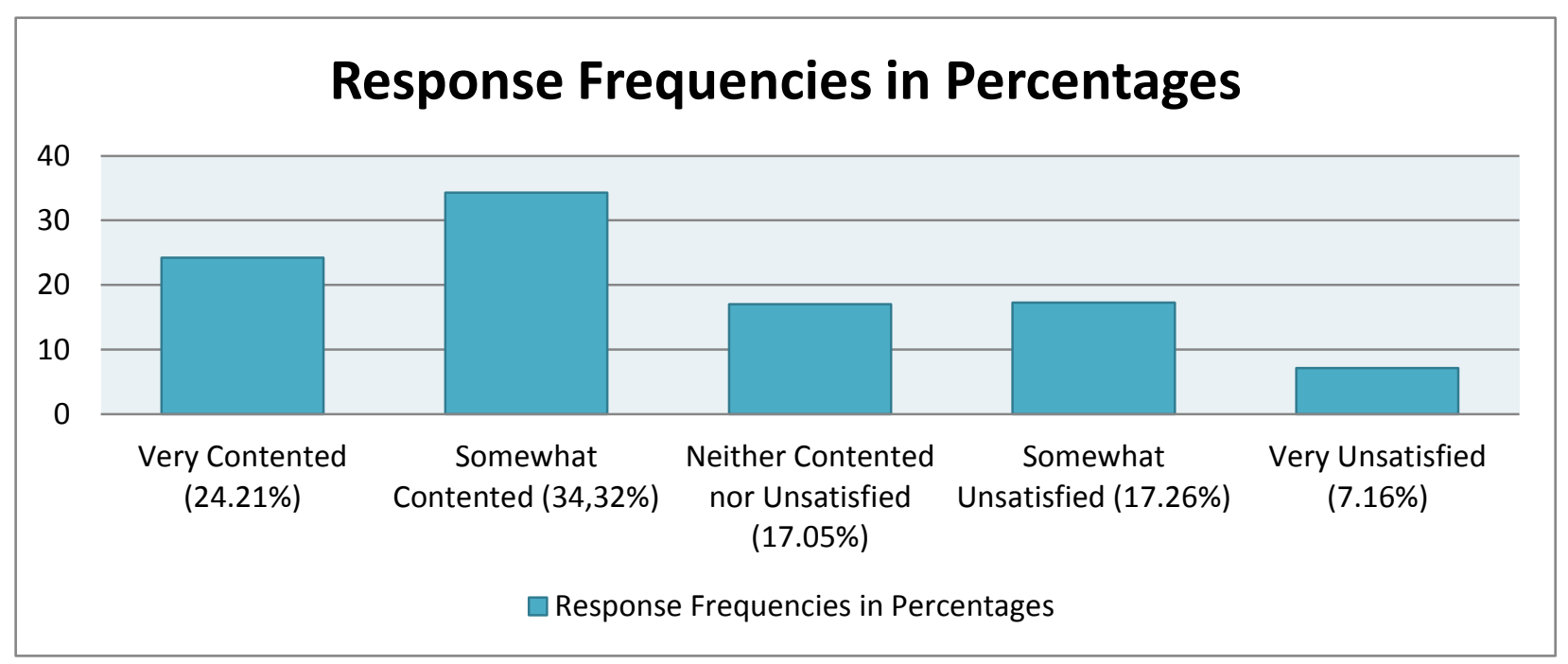

Figure 1. Responses frequencies for Hypothesis one (H01) in column chart

Source: Author's computation using data from field survey, 2020.

\subsubsection{Presentation of Data for Hypothesis Two (H02)}

Hypothesis two (H02) was utilized to appraise the relationship between Insurance Industry Operations variable, namely: 'Investment of Funds from Premium charged' and 'GDP Increase' in Nigeria. The question that captured the relationship in the variables in hypotheses two (H02) states thus:

'How delighted or unfulfilled would you say that 'Investment of Funds from Premium charged' by Insurance companies are contributing to 'GDP Increase' in Nigeria?

Table 3. Responses frequencies for Hypothesis two (H02)

\begin{tabular}{lcc}
\hline & Response Frequencies & $\begin{array}{c}\text { Response Frequencies in } \\
\text { Percentages (\%) }\end{array}$ \\
\hline Very Delighted & 106 & $22.32 \%$ \\
Somewhat Delighted & 161 & $33,89 \%$ \\
Neither Delighted nor Unfulfilled & 90 & $18.95 \%$ \\
Somewhat Unfulfilled & 71 & $14.95 \%$ \\
Very Unfulfilled & 47 & $9.89 \%$ \\
Total & 475 & $100 \%$ \\
\hline Sot & &
\end{tabular}

Source: Field Survey, 2020.

Table 3 displays the Response frequencies obtained for hypotheses two (H02) in absolute figures and also in percentages. Like the first hypothesis, the first two answer options in the table expressed delectation, the feeling of satisfaction. These together constitute 56.21\% of total responses implying that Investment of Funds from Premium charged' by Insurance companies are contributing to 'GDP Increase' in Nigeria. Though the magnitude of percentile so expressed is large enough to reject the null and accept the alternate hypothesis, it does indicate that the relationship between the variable is on the average, indicating a not too strong relationship. The Response frequencies expressed in percentages were utilized in computing the Column chart displayed in Figure 2. The chart clearly depicts the distinct characteristics of the frequencies of the answer options to the question. The answer options captioned 'Somewhat delighted' tops the group at 33.89\% and followed closely is the answer option captioned 'Very Delighted at $22.32 \%$. The least answer option is Very Unfulfilled standing at $9.89 \%$. 


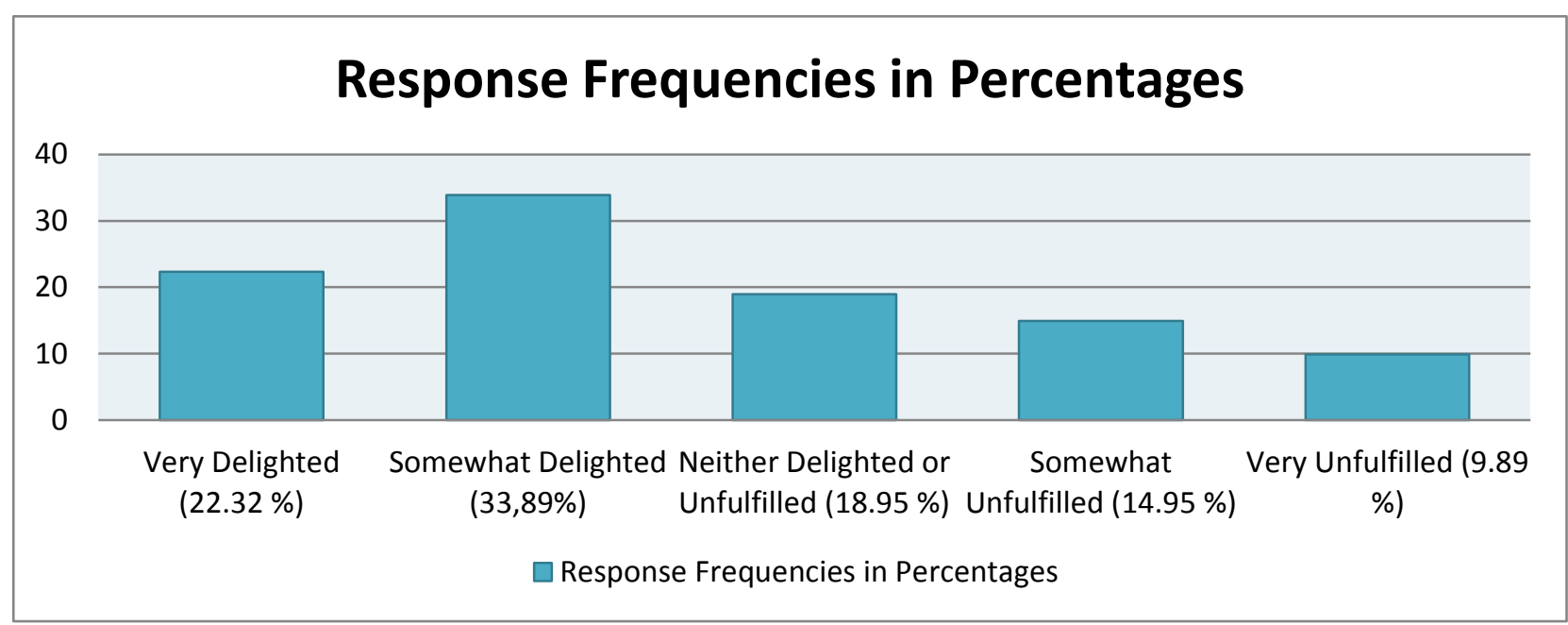

Figure 2. Responses frequencies for Hypothesis two (H02) in Column chart

Source: Author's computation using data from field survey, 2020

\subsubsection{Presentation of Data for Hypothesis Three (H03)}

Hypothesis three (H03) was employed to test the relationship between Insurance industry Operation's variable, namely 'Provision of Foreign Insurance Services' and 'GDP Increase' in Nigeria. Here, how much of cross-border services the Insurance industry in Nigeria have been rendering was brought to fore. These insurance transactions influence Balance of Payments (BoP) position and ultimately the enhancement of GDP Increase. The question that captured the relationship in the variables in hypothesis three (H03) states thus:

'How Satisfied or Dissatisfied would you say that the Provision of Foreign Insurance Services by Insurance companies has facilitated GDP Increase in the Nigerian economy?

The Response frequencies for hypothesis three (H03) and their percentages are shown in Table 4. The table shows that the variable, Provision of Foreign Insurance Services exhibited a distinct characteristic from other variables. Though the answer options indicating satisfaction made up $55.37 \%$ of total responses which is large enough to reject the null hypothesis, the proportion of respondents who are dissatisfied is also very large. It implies that a good number of respondents are of the opinion that Provision of Foreign Insurance Services by Insurance companies in Nigeria has not contributed much to GDP Increase in the economy. This is a fact to be considered seriously if stakeholders are serious about improving the contributions of that aspect of Insurance operations to the economy.

Table 4. Responses frequencies for Hypothesis three (H03)

Response Frequencies

\begin{tabular}{lcc}
\hline Very Satisfied & 116 & $24.42 \%$ \\
\hline Somewhat Satisfied & 147 & $30.95 \%$ \\
Neither Satisfied nor Dissatisfied & 36 & $7.58 \%$ \\
Somewhat Dissatisfied & 131 & $27.58 \%$ \\
Very Dissatisfied & 45 & $9.47 \%$ \\
Total & 475 & $100 \%$ \\
\hline
\end{tabular}

Source: Field Survey, 2020. 
Figure 3 displays the Responses frequencies for Hypothesis three (H03) in a Column chart. This shows distinctively the characteristics of the frequencies of the answer options. It indicates that the proportion of respondents satisfied that Provision of foreign Insurance services by Insurance companies in Nigeria enhanced GDP Increase almost approximate those dissatisfied plus those in doubt. The real fact is that foreign insurance services in Nigeria appear dwindling centered more or less on import transactions. More about this variable shall be revealed on computation of its PPMCC or $(r)$ and the Coefficient of Determination $\left(r^{2}\right)$.

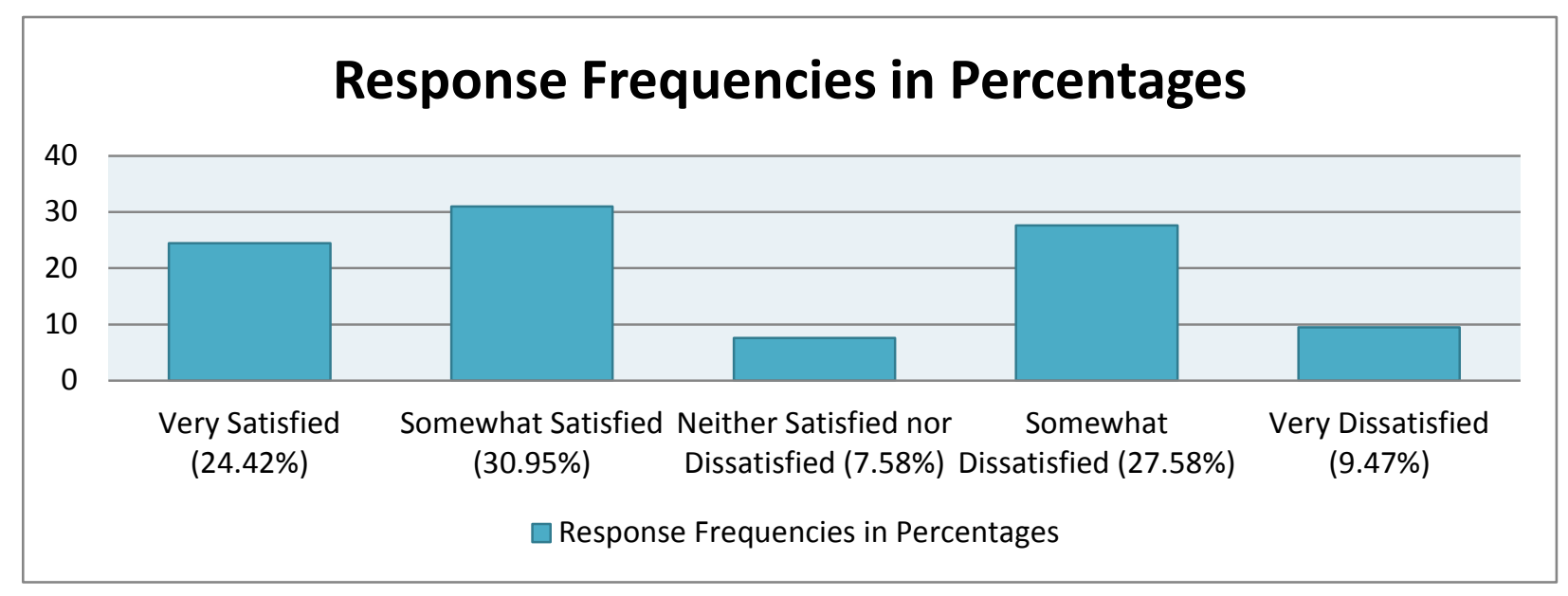

Figure 3. Responses frequencies for Hypothesis three (H03) in column chart

Source: Author's computation using data from field survey, 2020.

\subsection{Model Estimation}

Two exquisite and detailed statistical parameters were employed in the analysis of data in this study. They are PPMCC or (' $\mathrm{r}$ ') and the Coefficients of Determination $\left(\mathrm{r}^{2}\right)$. The values of the duo are computed in this section using equation 2 specified in section 3.3 and data obtained from field survey for each hypothesis. Tables were utilized here to derive the total value $(\Sigma)$ of the components in each model.

\subsubsection{Estimation of Hypothesis 1 (H01) Model}

Table 5. Derivation of PPMCC or (r) and $\left(\mathrm{r}^{2}\right)$ for Hypotheses One (H01) using the variable data

\begin{tabular}{lccccccc}
\hline & $\mathbf{X}$ & $\mathbf{Y}$ & $\mathbf{x}=\mathbf{X}-\ddot{\mathbf{X}}$ & $\mathbf{y}=\mathbf{Y}-\overline{\mathbf{Y}}$ & $\mathbf{X y}$ & $\mathbf{x}^{\mathbf{2}}$ & $\mathbf{y}^{\mathbf{2}}$ \\
\hline Very Satisfied & 5 & 115 & 2 & 20 & 40 & 4 & 400 \\
Somewhat Satisfied & 4 & 163 & 1 & 68 & 68 & 1 & 4624 \\
Neither Satisfied nor Dissatisfied & 3 & 81 & 00 & -14 & 00 & 00 & 196 \\
Somewhat Dissatisfied & 2 & 82 & -1 & -13 & 13 & 1 & 169 \\
Very Dissatisfied & 1 & 34 & -2 & -61 & 122 & 4 & 3721 \\
Total $\left(\sum\right)$ & 15 & 475 & 00 & 00 & 243 & 10 & 9110 \\
\hline
\end{tabular}

Source: Authors' computation, 2020.

Mean of Weighted Answer Options; $\quad \bar{X}=\frac{\sum X}{n}=\frac{15}{5}=3$

Mean of Frequency Response Options $\quad \bar{Y}=\frac{\sum Y}{n}=\frac{475}{5}=95$ 
From equation 2; PPMCC; $\mathrm{r}^{\mathrm{x}_{\mathrm{Y}}}=\frac{\sum x y}{\sqrt{\sum x^{2} \sum y^{2}}}=\frac{243}{\sqrt{10 x 9110}}=\frac{243}{301.83}=0.8051$

Therefore:

The Pearson's Product-Moment Correlation Co-efficient (PPMCC) or $\mathrm{r}^{\mathrm{x}_{\mathrm{\gamma}}}=0.8051$ and

The Coefficient of Determination $\left(\mathrm{r}^{2}\right)=(0.8051)^{2}=0.6482$ or $64.83 \%$.

4.2.2 Estimation of Hypothesis 2 (H02) Model

Table 6. Derivation of PPMCC or (r) and $\left(\mathrm{r}^{2}\right)$ for Hypotheses two (H02) using the variable data

\begin{tabular}{lccccccc}
\hline & $\mathbf{X}$ & $\mathbf{Y}$ & $\mathbf{x}=\mathbf{X}-\ddot{\mathbf{X}}$ & $\mathbf{y}=\mathbf{Y}-\overline{\mathbf{Y}}$ & $\mathbf{X y}$ & $\mathbf{x}^{\mathbf{2}}$ & $\mathbf{y}^{\mathbf{2}}$ \\
\hline Very Delighted & 5 & 106 & 2 & 11 & 22 & 4 & 121 \\
Somewhat Delighted & 4 & 161 & 1 & 66 & 66 & 1 & 4356 \\
Neither Delighted nor Dejected & 3 & 90 & 00 & -5 & 00 & 00 & 25 \\
Somewhat Dejected & 2 & 71 & -1 & -24 & 24 & 1 & 576 \\
Very Dejected & 1 & 47 & -2 & -48 & 96 & 4 & 2304 \\
Total $\left(\sum\right)$ & 15 & 475 & 00 & 00 & 208 & 10 & 7382 \\
\hline Sour
\end{tabular}

Source: Authors' computation, 2020

Mean of Weighted Answer Options; $\bar{X}=\frac{\sum X}{n}=\frac{15}{5}=3$

Mean of Frequency Response Options $\quad \bar{Y}=\frac{\sum Y}{n}=\frac{475}{5}=95$

From equation 2; PPMCC; $\mathrm{r}^{\mathrm{x}_{\mathrm{y}}}=\frac{\sum x y}{\sqrt{\sum x^{2} \sum y^{2}}}=\frac{208}{\sqrt{10 x 7382}}=\frac{208}{271.70}=0.7656$

Therefore:

The Pearson's Product-Moment Correlation Co-efficient (PPMCC) or $\mathrm{r}^{\mathrm{x}_{\mathrm{y}}}=0.7656$ and

The Coefficient of Determination $\left(\mathrm{r}^{2}\right)=(0.7656)^{2}=0.5861$ or $58.61 \%$.

4.2.3 Estimation of Hypothesis 3 (H03) Model

Table 7. Derivation of PPMCC or (r) and $\left(r^{2}\right)$ for Hypotheses three (H03) using the variable data

\begin{tabular}{lccccccc}
\hline & $\mathbf{X}$ & $\mathbf{Y}$ & $\mathbf{x}=\mathbf{X}-\ddot{\mathbf{X}}$ & $\mathbf{y}=\mathbf{Y}-\overline{\mathbf{Y}}$ & $\mathbf{x y}$ & $\mathbf{x}^{\mathbf{2}}$ & $\mathbf{y}^{\mathbf{2}}$ \\
\hline Very Satisfied & 5 & 116 & 2 & 21 & 42 & 4 & 441 \\
Somewhat Satisfied & 4 & 147 & 1 & 52 & 52 & 1 & 2704 \\
Neither Satisfied nor Dissatisfied & 3 & 36 & 00 & -59 & 00 & 00 & 3481 \\
Somewhat Dissatisfied & 2 & 131 & -1 & 36 & -36 & 1 & 1296 \\
Very Dissatisfied & 1 & 45 & -2 & -50 & 100 & 4 & 2500 \\
Total $\left(\sum\right)$ & 15 & 475 & 00 & 00 & 158 & 10 & 10422 \\
\hline Sour
\end{tabular}

Source: Authors' computation, 2020. 
Mean of Weighted Answer Options; $\bar{X}=\frac{\sum X}{n}=\frac{15}{5}=3$

Mean of Frequency Response Options $\quad \bar{Y}=\frac{\sum Y}{n}=\frac{475}{5}=95$

From equation 2; PPMCC; $\mathrm{r}^{\mathrm{x}_{\mathrm{y}}}=\frac{\sum x y}{\sqrt{\sum x^{2} \sum y^{2}}}=\frac{158}{\sqrt{10 x 10422}}=\frac{158}{322,83}=0.4894$

Therefore:

The Pearson's Product-Moment Correlation Co-efficient (PPMCC) or $\mathrm{r}^{\mathrm{x}_{\mathrm{y}}}=0.4894$ and

The Coefficient of Determination $\left(r^{2}\right)=(0.4894)^{2}=0.2396$ or $23.96 \%$

\section{Discussion of Findings, Conclusion and Recommendation}

\subsection{Discussion of Findings}

The analysis of result in this research study is in accordance with the decision rule of Pearson Product-Moment Correlation Coefficient (PPMCC) or ' $r$ ' as stated above. It is necessary here to highlight some basic facts about the parameter (PPMCC) or ' $r$ '. It serves to measure the strength and direction of linear relationship between variables in a model. The Coefficient of determination $\left(\mathrm{r}^{2}\right)$ measures the proportion of total variation in the dependent variable $(\mathrm{Y})$ that is explained by the independent variable $(\mathrm{X})$ in the model. It gives vital information about the goodness of fit of the model; how well the model appropriates the real data points such that $r^{2}$ value of 1.0 indicates that the model fits the data perfectly. The results for the computed values of ' $r$ ' and ' $r$ ' for the three hypotheses tested are displayed in Table 8 for ease of reference and discussion.

Table 8. Results of empirical estimations for analysis

\begin{tabular}{lcc}
\hline \multicolumn{1}{c}{ Hypotheses } & $\begin{array}{c}\text { PPMCC } \\
(\mathbf{r})\end{array}$ & $\begin{array}{c}\text { Coefficient of } \\
\text { Determination }\left(\mathbf{r}^{2}\right)\end{array}$ \\
\hline $\begin{array}{l}\text { H01: On 'Offering of flFinancial protection to Consumers' } \\
\text { and GDP Increase' }\end{array}$ & 0.8051 & $64.83 \%$ \\
$\begin{array}{l}\text { H02: On 'Investment of Funds from Premium charged' and } \\
\text { GDP Increase' }\end{array}$ & 0.7656 & $58.61 \%$ \\
$\begin{array}{l}\text { H03: On 'Provision of Foreign Insurance Services' and GDP } \\
\text { Increase' }\end{array}$ & 0.4894 & $23.96 \%$ \\
\hline
\end{tabular}

Source: Authors' Computation, 2020

For the remaining part of this discussion, we wish to present facts logically and sequentially to ease understanding. Hypothesis 1 (H01) model was used to test the relationship between Insurance Industry Operation's variable: Offering of financial protection to Consumers and GDP Increase in Nigeria. As the table shows, the value of the Pearson Product-Moment Correlation Coefficient (PPMCC) or ' $r$ ' for this model stood at 0.8051 indicating a very strong positive linear relationship between the variables. Besides, the Coefficient of determination $\left(\mathrm{r}^{2}\right)$ stood at $64.83 \%$ implying that the independent variable, 'Offering of financial protection to Consumers' explained $64.83 \%$ variation in the dependent variable - GDP Increase. These results mean that the model passed the test of significance. On that ground, we are compelled to reject the null hypothesis and accept the alternate hypothesis that there is a strong positive relationship and between Offering of financial protection to Consumers by Insurance companies and GDP Increase in Nigeria. It reflects that the variable: 'Offering of financial protection to Consumers' has the ability to increase economic activities that can positively facilitate GDP Increase in Nigeria. Therefore, the variable can be considered relevant to policies formulated to affect GDP Increase in Nigeria.

The relationship between Insurance Industry Operation's variable: Investment of funds from Premium charged and GDP Increase in Nigeria was tested with Hypothesis 2 (H02) model. The results in Table 8 show that the value of Pearson Product-Moment Correlation Coefficient (PPMCC) or ' $r$ ' stood at 0.7656 . This portends that the relationship 
between the variables is positive and is $76.56 \%$ strong in Nigeria. This degree of relationship clearly shows that the variable: 'Investment of funds from Premium charged' has made relevant contributions to GDP Increase in the Nigeria. Its Coefficient of determination $\left(\mathrm{r}^{2}\right)$ stood at $58.61 \%$ indicating that the independent variable explained such degree of variation in the dependent variable - GDP Increase. It also means that the model appropriates the real data points well to $58,61 \%$ which portrays a fair goodness of fit of the model. With these results and coupled with the results from the Column chart, we reject the null hypothesis and accept the alternate hypothesis. In real terms, there is a positive and strong relationship between the variables: Investment of funds from Premium charged by Insurance companies and GDP Increase in Nigeria.

The third model relates to the testing of Hypothesis 3 (H03). Specifically, it tested the relationship between Insurance Industry operations variable: 'Provision of Foreign Insurance Services and GDP Increase in Nigeria. The value of Pearson Product-Moment Correlation Coefficient (PPMCC) or ' $r$ ' for this variable stood low at 0.4894 and its accompanying Coefficient of Determination $\left(\mathrm{r}^{2}\right)$ is equally very low at $23.96 \%$. By implication, the results indicate that the strength of relationship between the variables though positive, it is considered very moderate, thus reflecting that the variable have had only moderate impact on GDP Increase in Nigeria. Besides, the variable was only able to explain 23.96\% variations in GDP Increase. The magnitude of this result suggests that the variable failed the test of significance. Thus, the results cast doubts on whether the variable 'Provision of Foreign Insurance Services' could be considered relevant to policies that are formulated to affect GDP Increase in Nigeria. Obviously, considering the economic environment in Nigeria and Insurance Industry operations that is to a large extent confined internally, expectations were that this variable may fail the test of significance. Indeed, the results conformed to aprori expectation. Unlike the Euro-Area striving for a single financial market, where economic cooperation amongst member States is strong and breeding intensive cross-border transactions that encourages insurance diversification, the ECOWAS sub-region has not developed such feats. So, operations of the Insurance Industry in member States of ECOWAS are more or less internal such that provision of foreign insurance services is very minimal. This may explain why this variable: Provision of Foreign Insurance Services' failed the test of significance and may not have contributed much to GDP Increase in Nigeria.

\subsection{Conclusion}

This study carried out a fundamental analysis of Insurance Industry Operations and GDP Increase in Nigerian. We based the conclusions on the results of the empirical estimation carried out and as per discussions of findings above. We had three variables namely: 'Offering of financial protection to Consumers; 'Investment of Funds from Premium charged' and 'Provision of Foreign Insurance Services'. These variables served as proxy for Insurance Industry Operations used as independent variables to explain the dependent variable, GDP Increase. For the first hypothesis (H01), the Pearson Product-Moment Correlation Coefficient (PPMCC) or ' $r$ ' for this model stood at 0.8051 affirming a positive and strong relationship and its corresponding Coefficient of determination $\left(\mathrm{r}^{2}\right)$ stood at $64.83 \%$. These results compelled us to reject the null hypothesis and accept the alternate hypothesis, thus we concluded that there is a positive and strong relationship between Offering of financial protection to Consumers by Insurance companies and GDP Increase in Nigeria.

The results of the second hypothesis (H02) are equally robust, though its statistical values are less compared to the first one. In H02 model estimation, Pearson Product-Moment Correlation Coefficient (PPMCC) or ' $r$ ' stood considerably well at 0.7656 or $76.56 \%$ and its accompanying Coefficient of determination $\left(\mathrm{r}^{2}\right)$ stood moderately at $58.61 \%$. These results also necessitated the conclusion that there is a positive and strong relationship between the variable 'Investment of funds from Premium charged by Insurance companies and GDP Increase in Nigeria. On this note, the variable, 'Investment of funds from Premium charged' can be considered relevant to policies formulated to affect GDP Increase in Nigeria.

The estimation of hypothesis (H03) model with variables: 'Provision of Foreign Insurance Services and GDP Increase' showed relatively different characteristics in the values of the two statistical parameters employed for the empirical analysis. The Pearson Product-Moment Correlation Coefficient (PPMCC) or ' $r$ ' for the model stood at 0.4894 and its attendant Coefficient of Determination $\left(r^{2}\right)$ stood at $23.96 \%$. While the value of PPMCC or ' $r$ ' is positive and may be said to be on the average or moderately strong as it could be approximated $50 \%$, the value of Coefficient of Determination $\left(\mathrm{r}^{2}\right)$ is pretty low and failed the test of statistical significance. By implication, there exist a positive relationship but the strength of relationship of the variables is moderately low. Considering the low value of the Coefficient of Determination $\left(\mathrm{r}^{2}\right)$ which indicates that the independent variable explained just $23.96 \%$ variation in GDP Increase, we are impelled to conclude that the variable's contribution to GDP Increase is very minimal. Based on these outcomes, it cast doubts on whether the variable can be considered relevant to policies that are formulated to affect GDP Increase in Nigeria. 


\subsection{Recommendations}

Deductions from empirical and theoretical literatures reviewed above and the results from this study showed that Insurance is critical to the success of businesses and indeed, it is an integral part of overall business operations. There is a consensus that Insurance operations affect macroeconomic variables positively and play very crucial roles in an economy. In this study, these facts were brought to light particularly in the results from hypothesis (H01) and hypothesis (H02) model estimations. Insurance Industry Operations' variables in these two models passed the test of statistical significance and could be considered relevant to policies formulated to affect GDP Increase in Nigeria. From the foregoing, we recommend that Management of companies in the Insurance industry should seek to enhance strategies of service delivery in order to expand the service of financial protection to Consumers. Expanding these services to more business areas with attractive incentives to win more customers will lead to the purchase of more policies and that will ultimately generate more funds for investments. This way, businesses will be strongly positioned for more vibrant economic activities with a goal to increasing GDP.

The results of hypothesis (H03) appear cumbersome, difficult and unwieldy to draw inferences. While the value of PPMCC or ' $r$ ' at 0.4894 attests to a positive and moderately strong linear relationship, the value of the Coefficient of Determination $\left(\mathrm{r}^{2}\right)$ at $23.96 \%$ is low and failed the test of statistical significance. In our discussion of findings, we attempt to explain that it may be due to lack of diversification of Insurance services across-border to neighboring ECOWAS member States or other countries. The variable: Provision of Foreign Insurance Services' can only yield dividends and contribute or enhance Balance of Payments when insurance services are exported abroad. So we recommend that deliberate and sustained efforts should be made by stakeholders to export insurance products across border to businesses in other countries. This will require increased professionalism, knowledge, and modern infrastructures. On this note, we recommend that Management of Insurance companies should bridge the gap by training and re-training of employees and also the acquisition of necessary innovative technologies is paramount.

\section{References}

Chikeleze, \& Echekoba. (2008). Insurance Business and Information Communication Technology; Nigeria Insurance Industry Experience. International Journal of Business and Management Invention, 2(10), 19-31. Retrieved from: www.ijbmi.org

Diacon, S. R., \& Carter, R. L. (2007). Success in Insurance. Lonon, John Murray publishers Ltd.

Etale, L. M. (2019) Insurance Sector Development and Economic Growth in Nigeria: An Empirical Analysis. International Journal of Development and Economic Sustainability, 7(4), 34-48.

Haykn, K. (2014). The Role of Insurance in the World economy and its effect to macroeconomic indicators. Retrieved from https://euroasia-science.ru/ekonomicheskie-nauki

Igbodika, M., Ibenta, S. N., \& Isaac, J. E. (2016). The contribution of insurance investment toeconomic growth in Nigeria; 1980-2014. International Journal of Advanced Studies inBusiness Strategies and Management, 4(1), 110-123.

Iowa Insurance Institute. (2020). How the insurance industry helps stimulate the economy. Retrieved from http/www/Insurance articles/How the insurance industry helps stimulate the economy $\% 20 \% 20$ Iowa Insurance Institute.htm

Oyedotun, T. M., \& Adesina, B. D. (2015). Nexus between economic growth and insurance business in Nigeria. Research Journal of Finance and Accounting, 6(9), 142-149.

Ozuomba, C. V. (2013). Impact of Insurance on Economic Growth in Nigeria. International Journal of Business and Management Invention, 2(10), 19-31. Retrieved from www.ijbmi.org

Sajid, M., Arpah, A., \& Angappan, R. (2017). Does insurance promote economic growth: A comparative study of developed and emerging/developing economies. Cogent Economics \& Finance, 5(1). Retrieved from https://www.tandfonline.com/doi/full/10.1080

Sumegi, K., \& Haiss, P. (2006). The relationship of insurance and economic growth, a theorical and empirical analysis. Ecomod Conference, Hong Kong, Retrieved from Online.

Ward, D., \& Zurbruegg, R. (2000). Does insurance promote economic growth? Evidence from OECD countries. The Journal of Risk and Insurance, 67(4), 489-506.

Weisbart, S. (2018). How Insurance drives Economic Growth. Retrieved from https://www.iii.org/sites/default/files/docs/pdf/insurance-driver-econ-growth

Wronski L. (2018). Let's agree NOT to use agree/disagree questions. Retrieved from https://www.surveymonkey.com/curiosity/lets-agree-not-use- 